\title{
Funebria incaica en el cerro Esmeralda (Iquique, I región)
}

JORGE CHECURA J. ${ }^{1}$

\section{Introducción}

Durante la construcción de un camino al este de Iquique, a 905 m.snm, en la cordillera costera de los Andes, en el cerro denominado Esmeralda, se encontró un entierro de dos personas. El Museo de Iquique dio cuenta que el hallazgo es de suma importancia, y podría tener significado sobre la evidencia de los incas en la zona que es relativamente poco conocida. En este artículo informamos sobre el ajuar que ha sido encontrado en este entierro.

El cerro Esmeralda se ubica en la región de la cordillera de la Costa, inmediatamente al noroeste de la ciudad de Iquique, a $20^{\circ} 13^{\prime}$ Lat. S y $70^{\circ} 8^{\prime}$ Long. O; es parte del sector norte de la línea de contacto de la falla tectónica denominada quebrada de Huantaca (Figura 1).

El hallazgo fue hecho casualmente, provocado por una explosión de dinamita durante la construcción de un camino que termina en la cumbre, según el informe del señor Gustavo Rojas Williams, a cargo de la obra. Los dos cuerpos estaban depositados en la cumbre principal, a $3.50 \mathrm{~m}$ de profundidad, con estratos alternados de piedra y arena depositadas artificialmente. Las paredes vírgenes de la excavación son compactas y de roca pura.

La información oral de varias personas coincide en que las medidas de este enterratorio serían aproximadamente: profundidad, $3.50 \mathrm{~m}$, radio, $1,50 \mathrm{~m}$. Su forma circular u ovoidal no fue posible establecerla claramente.

Los cuerpos se encontraban en posición fetal y decúbito dorsal con las piernas semiflectadas; el primero de ellos corresponde a una niña de aproximadamente nueve años de edad con una estatura de $1.14 \mathrm{~m}$. El segundo cuerpo, de igual sexo, es de

1 Universidad del Norte, Iquique, CHILE. un adulto joven de 18 a 20 años aproximadamente, con una estatura de $1.61 \mathrm{~m}$.

Ambos cráneos son braquicéfalos sin deformaciones naturales o artificiales. Los cadáveres se presentan momificados por deshidratación natural, con los rostros cuidadosamente cubiertos por un textil muy fino. No se encontraron pinturas. Aparte de las alteraciones causadas por la excavación, no se aprecia ninguna mutilación o alteración física que estuviera asociada a un ritual especial.

La mayor y más importante pieza textil parece haber sido removida y debe atribuírsele a la momia adulta, ya que los pliegues y marcas se adaptan a su cuerpo; también corresponden a ésta los brazaletes de oro y plata. La cerámica debe ser considerada como común a todo el enterramiento ya que se omitió hacer los registros adecuados debido a que las personas que excavaron, por desconocimiento de las técnicas arqueológicas, no observaron este detalle.

Las momias estaban vestidas de manera diferente, lo que permitiría distinguir dos condiciones sociales; aunque complementadas, son diferentes entre sí. Ambas utilizan tejidos de alpaca de igual color, el cuerpo del adulto posee la mayor parte del ajuar que además está confeccionado con más lujo; los colores predominantes de los textiles son el amarillo y el rojo. También se encuentran en menor cantidad los colores naturales de la lana blanca, café oscura y negras. Se encontró disperso en uno de los mantos una pequeña cantidad de bermellón de cinabrio, material que utilizaban las doncellas de la realeza para su maquillaje.

La evidencia braquicefálica y la presencia del torus palatinus permiten ubicar los cadáveres como pertenecientes a indígenas peruanos. La fineza de los textiles como también el que no se encontrara algodón en las fibras tejidas induce a pensar que su procedencia puede ser situada en el Cusco o alrededores. 


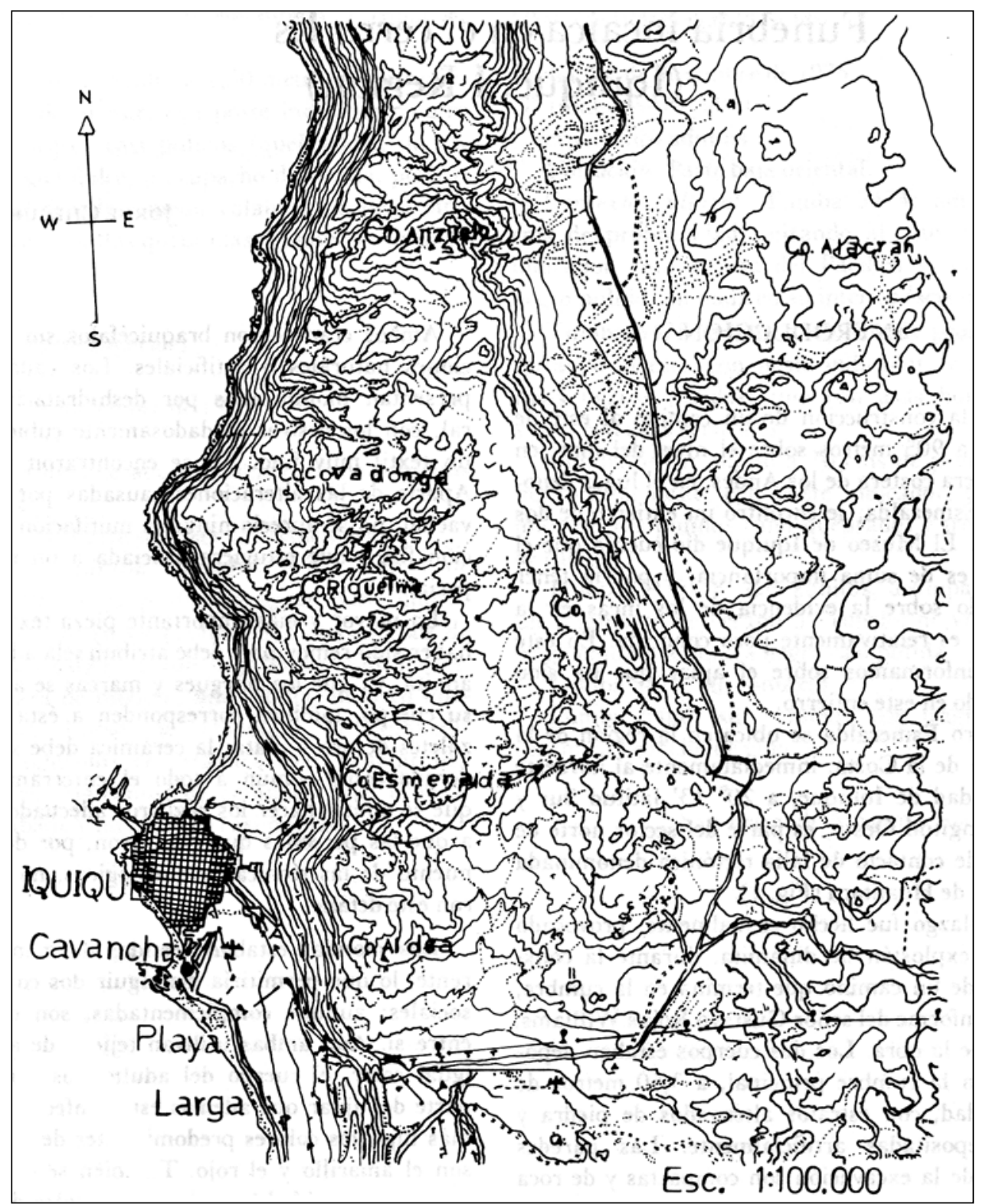

Figura 1. Ubicación del cerro Esmeralda.

Precisamente es Garcilaso de la Vega (1604: IV Cap. II) quien describe la dedicación de las doncellas escogidas a la confección de finos textiles que se usaban no sólo para vestir al Inka y a su grupo real, sino que también para los sacrificios de adoración al Sol. Casi todas las prendas tejidas descritas por Garcilaso están presentes en el ajuar encontrado en el cerro Esmeralda.

\section{Informe anatomopatológico}

Anatomía descriptiva. Sujeto de sexo femenino, de aproximadamente 20 años de edad. Mediciones antropométricas: distancia maléolo tibial-planta del pie, $6 \mathrm{~cm}$; tibia derecha, $33.5 \mathrm{~cm}$; fémur derecho, $41 \mathrm{~cm}$; húmero izquierdo, $29.5 \mathrm{~cm}$; cúbito izquierdo, $25 \mathrm{~cm}$; mano izquierda (carpo, metacarpo, dedos), $21 \mathrm{~cm}$; altura máxima del cráneo, $15.3 \mathrm{~cm}$; columna vertebral, $65.1 \mathrm{~cm}$. Promedio altura cuerpos vertebrales: cervicales 
$10 \mathrm{~mm}, 7 \mathrm{~cm}$; dorsales $17 \mathrm{~mm}, 20.4 \mathrm{~cm}$; lumbares $29 \mathrm{~mm}, 14.5 \mathrm{~cm}$; sacro $102 \mathrm{~mm}, 10.2 \mathrm{~cm}$. Altura total discos intervertebrales: $20 \%$ longitud de la columna, $13 \mathrm{~cm}$; estatura aproximada $160.9 \mathrm{~cm}, 1.61 \mathrm{~m}$; valores de corrección $-2 \mathrm{~cm}, 1.59 \mathrm{~m}$. Craneometría: diámetro anteroposterior máximo, $17 \mathrm{~cm}$; diámetro bregma-opistión, $15.3 \mathrm{~cm}$; diámetro transversal máximo, $14.2 \mathrm{~cm}$; índice cefálico, $83.52 \mathrm{~cm}$; cráneo braquicéfalo, ángulo esferoidal de Welker, $126^{\circ}$.

Anatomía radiológica. Desde el punto de vista de la indemnidad anatómica de la pieza y de sus estructuras óseas, no sé aprecian fracturas ni deformaciones. Las piezas dentarias se observan en buen estado. Las suturas del cráneo corresponden a un adulto joven. La disposición de la columna cervical observada en la toma lateral confirma la semiflexión de cabeza. A este nivel no se aprecian fracturas ni otros tipos de lesiones osteoarticulares.

Se han trazado los diámetros anteroposterior máximo, transversal máximo y bregma opistioniano. Además se ha medido en ángulo esferoidal de Welker que es igual a $126^{\circ}$ (cráneos asiáticos $\overline{\mathrm{x}}-124^{\circ}$ ). El desarrollo de la porción facial guarda armonía con el de la caja craneana.

Anatomía patológica. Sujeto parcialmente destruido, con signos de momificación. Decúbito dorsal, con inclinación de la cabeza adelante y a derecha, flexión de cadera y rodillas con abducción y rotación externa de fémures, pies en flexión plantar, miembros en abducción brazos-manos en posiciones intermedias.

El sujeto presenta fracturas costales múltiples en el hemitórax izquierdo, destrucción parcial de la columna vertebral, arrancamiento del miembro superior izquierdo incluido el cinturón escapular, arrancamiento del antebrazo derecho, transposición de la articulación radiocubital superior y destrucción de la paleta humeral derecha. En los miembros inferiores se constata pérdida casi total de los tejidos del muslo y pierna derecha, ausencia del pie de ese segmento y desarticulación tibiaperonea.

Presenta, además, innumerables escoriaciones, laceraciones y pérdidas parciales del tejido en diversas partes del cuerpo y demás segmentos. Tanto las lesiones osteoarticulares como estas últimas son producto, sin lugar a dudas, de las maniobras y manipulaciones de que fue objeto la momia al ser sacada del enterramiento. No obstante, llama la atención la transposición de la articulación radiocubital superior derecha, que al momento del examen se encontraba notablemente rígida, todo lo cual hace suponer que se trata de una lesión antigua y no necesariamente causada en forma intencional.

Este hecho, que no deja ser una mera suposición, debería tomarse en cuenta pero con la debida cautela, por cuanto es a nivel de articulación donde toman lugar los movimientos de giro de la muñeca (pronosupinación). El examen de la cabeza y de la región cervical permite establecer que la causa probable de su muerte fue estrangulación. Los indicadores para fijar esta hipótesis son los siguientes: a) marcas que se sitúan por debajo del maxilar y que se extienden desde el borde anterior del esternocleidomastoideo derecho al borde anterior del esternocleidomastoideo izquierdo; b) erosión profunda en el vientre del esternocleidomastoideo derecho, inmediatamente por debajo del ángulo del maxilar; c) depresión del vientre muscular del esternocleidomastoideo izquierdo de dirección anteroposterior y de un diámetro transversal de $2 \mathrm{~cm}$, aproximadamente; d) depresión similar en el esternocleidomastoideo derecho, por debajo de la inserción mastoidea y con formación de un reborde de tejido que la limita hacia la raíz del pelo.

La probable posición del sujeto en el momento de su muerte es la descrita a continuación: sentado con las piernas cruzadas al estilo Buda, brazos apoyados relajadamente sobre los muslos, cabeza péndula sobre el pecho, apoyando el costado derecho del mentón sobre la clavícula de ese lado.

Numerosas son las evidencias que parecen indicar que el individuo que se encontraba en esa posición estaba en estado de relajación. Al respecto cabe señalar algunos hechos adicionales: la cabeza se encuentra inclinada hacia la derecha, con flexión de cuello; el mentón deprimido y la mandíbula descendida dejando al descubierto la cavidad bucal.

En el reborde del maxilar inferior, inmediatamente a la derecha del vértice del mentón, aparece una depresión limitada por un pliegue de piel, que hace suponer el apoyo de esa zona sobre la clavícula derecha. La mejilla derecha se separa de las piezas dentarias de ese lado dejando expuesto el vestíbulo de la cavidad oral, lo que contrasta con el aplanamiento de la mejilla opuesta. La lengua desviada a la derecha, descansa sobre los molares de la arcada inferior y los tejidos blandos del istmo de las fauces (capilares y velos del paladar) se desvían igualmente a la diestra. 
Los párpados se encuentran cerrados, las manos en posiciones intermedias, los dedos ni flectados ni totalmente ni extendidos, las piernas flectadas y los muslos abducidos.

Se podría suponer que el sujeto fue sacrificado estando en posición sedente y sin ofrecer resistencia, por estar probablemente drogado o en estado de semiinconciencia.

Anatomía descriptiva. Sujeto de sexo femenino, de aproximadamente nueve años de edad, determinada por su fórmula dentaria. Mediciones antropométricas (longitud de segmentos corporales): distancia maléolo tibial-planta del pie, $5 \mathrm{~cm}$; tibia, $23 \mathrm{~cm}$; fémur, $27 \mathrm{~cm}$; húmero, $20 \mathrm{~cm}$; cúbito, $16 \mathrm{~cm}$; mano, $14 \mathrm{~cm}$; altura máxima del cráneo, $13 \mathrm{~cm}$; longitud columna vertebral, $48 \mathrm{~cm}$; estatura estimativa, $116 \mathrm{~cm}$ $(1.16 \mathrm{~m})$; valores de corrección $-2.0 \mathrm{~cm}, 1.1-4 \mathrm{~m}$. Craneometría: diámetro anteroposterior máximo, $16.6 \mathrm{~cm}$; diámetro bregma-opistión, $13 \mathrm{~cm}$; diámetro transversal máximo, $13 \mathrm{~cm}$; índice cefálico, $81.9 \mathrm{~cm}$; fórmula dentaria,

$\begin{array}{cccccc}2 & 1 & 1 & 4 & 1 & -{ }^{2} \\ 2 & \mathrm{P} & \mathrm{C} & \mathrm{I} & \mathrm{C} & \mathrm{P}\end{array}$

Anatomía patológica. Sujeto en estado de momificación, sin grandes signos de deterioro. Cabeza inclinada hacia adelante semiflexión del cuello, mentón deprimido y proyectado hacia anterior, abducción dentaria completa, miembros superiores abducidos, codos semiflectados, miembros inferiores abducidos, flexión de caderas, rodillas y tobillos, con desviación de los ejes femorales hacia la derecha.

El sujeto presenta perforación con fracturas costales a nivel del mentón derecho, de $6 \mathrm{~cm}$ de diámetro. Pérdida de tejidos a nivel de la región auricular derecha y del labio inferior. Pérdida total de ambos pies por delante de la articulación tarsometatarsiana.

En un primer examen el individuo no presenta signos que permitan evidenciar la causa precisa y necesaria de su muerte. No obstante son dignos de mencionar los siguientes elementos descriptivos: el maxilar inferior se proyecta hacia adelante aproximando la lengua en la oclusión de las arcadas.

Un surco de cierta semejanza al descrito en el informe anterior rodea la base del cráneo, inmediatamente por debajo del plano maxilar inferior. Asimismo se observan erosiones con pérdida de tejidos en el hueco supraclavicular y vientre del esternocleidomastoideo izquierdo. El estudio de la cavidad bucal no revela la inclusión de tierra ni de cuerpos extraños. El rictus facial no es prueba concluyente de que el individuo tuviera sufrimientos previos al instante de su muerte, pero indudablemente su expresión contrasta con las facies del individuo descrito anteriormente.

El sujeto probablemente se encontraba en posición de sedentación en cuclillas, al instante de su inhumación. La perforación situada en el hemotórax derecho contrasta con la perforación similar mayor en el hemotórax del primer sujeto. De acuerdo a la descripción, es factible que ambos individuos estuvieran situados de modo tal que este último se encontraba por detrás y a la izquierda el primero, apoyándose el uno con el otro. En cuanto a su causa de muerte, no hay razón para pensar que se ha variado el modus operandi del primer caso. En cuanto a su raza, puede suponerse también como perteneciente a la raza asiática, aunque para confirmarlo tan sólo se obtuvo el índice cefálico que determinó una braquicefalia, perfectamente aceptable debido a la edad y desarrollo del individuo.

\section{Descripción de los ceramios (Figuras 2 y 3)}

Tiesto 1. Pasta antiplástica: Arena de granulo-metría mediana con cuarzo y biotita, la distribución del antiplástico es regular; el color de la pasta es café pardo uniforme sin núcleo. La textura compacta, sin bolsillo de aire. Fractura regular. Cocción: oxidante uniforme. Medidas: alto total, $42.5 \mathrm{~cm}$; ancho máximo, $26 \mathrm{~cm}$. Grosor promedio, $5.5 \mathrm{~mm}$. Superficie externa es de color rojo engobado pulido, e interna color café pardo alisado con ramas vegetales. Manufactura: modelamiento de base y pie. Rasgos zona del cuerpo: forma general, pieza del cuerpo ovoidal en posición normal. Forma de la base: cónica de dos líneas convergentes que terminan en el comienzo de un soporte hiperbólico. Carece de pintura; su decoración integrada a la superficie adorna las dos protuberancias que se ubican en el sector superior del cuerpo y en el lado grueso del asa; los rasgos de la zona del cuello son de forma evertida y bordes redondos. Forma de la boca: esferoide. Aditamentos: asa en cuerpo, sobrepasando el nivel del borde de la pieza. Forma y estructura de los soportes: soporte hiperbólico que sirve de apoyo total de la vasija, su parte inferior termina en una base cóncava. 
Tiesto 2 (no decorado). Pasta antiplástica: Arena de granulometría gruesa con cuarzo y biotita; la distribución del antiplástico es regular; color de la pasta: anaranjado claro. Textura compacta sin bolsillos de aire. Fractura irregular. Cocción: oxidante parcial. Manufactura: modelamiento del pie y la base, sistema de rollos en el continente del ceramio. Medidas: alto total (sin asa), $20.3 \mathrm{~cm}$; ancho máximo (con asa), $17.2 \mathrm{~cm}$. Grosor promedio, $5.5 \mathrm{~mm}$. Superficie externa es de color café claro a obscuro con manchas de cocción pulido, e interna color café claro pulido. Rasgo zona del cuerpo: vasija del cuerpo, ovoidal. Forma de la base: cónica de dos líneas convergentes que terminan en el comienzo de un soporte hiperbólico. Pintura ausente. Zona del cuello: forma del cuello, evertido; forma del borde, semirredondo; forma de la boca: esferoide. Aditamentos: asa en cuerpo, sobrepasando el nivel del borde superior. Pintura ausente. Forma y estructura de los soportes: soporte hiperbólico que sirve de apoyo total de la vasija; su parte inferior termina en una base con una cavidad inferior. Su estructura es maciza.

Tiesto 3 (decorado). Pasta antiplástica: Arena de granulometría mediana con cuarzo y biotita. Distribución del antiplástico: uniforme. Color de la pasta: café claro. Textura: compacta sin bolsillos de aire. Fractura: irregular. Cocción: oxidante parcial. Manufactura: sistema de rollos en el continente y moldeamiento en la base y el pie. Medidas: ancho máximo, $11 \mathrm{~cm}$; altura total, $15.5 \mathrm{~cm}$. Grosor promedio, $4.5 \mathrm{~mm}$. Superficie externa es de color rojo con manchas obscuras de cocción engobada; interno color rojo pulido; borde del labio: engobado. Vasija de forma ovoidal en posición normal. Forma de la base: cónica; dos líneas convergentes finalizan en el comienzo de un soporte hiperbólico. Forma del cuello: evertido. Forma del borde: semirredondo. Forma de la boca: esferoide. Pintura ausente. Aditamento: asa clasificada como posición de asas en el cuerpo; sobrepasando el nivel del borde superior. Pintura ausente. Forma y estructura del soporte: hiperbólico que sirve de apoyo total de la vasija, su parte inferior termina en una base con una cavidad interior. Su estructura es maciza.

Tiesto 4 (no decorado). Pasta antiplástica: Siena con cuarzo y biotita. Distribución antiplástica: regular, uniforme. Color pasta: anaranjada. Textura: compacta. Fractura: regular. Cocción: oxidante parcial, presenta núcleo. Medidas: altura total, $44.5 \mathrm{~cm}$; ancho máximo, $28.3 \mathrm{~cm}$. Grosor promedio, $7 \mathrm{~mm}$. Superficie externa: color violáceo engobado. Tratamiento: bruñido. Interna: color café claro. Tratamiento: pulido. Forma general: vasija de forma ovoidal en posición normal. Forma de la base: cónica; las dos líneas convergentes terminan en una pequeña base de $3 \mathrm{~cm}$ de diámetro. Forma del fondo: cónico, terminado redondo en la parte opuesta a la pequeña base. Pintura ausente. Decoración integrada a la superficie. Ornamentación: zoomorfa en la parte superior del cuerpo. Zona del cuello: forma cuello hiperbólico. Forma del borde: perpendiculares. Forma de la boca: esferoidal. Pintura ausente. Aditamento: dos asas con posición de asa en el cuerpo y en línea vertical.

Tiesto 5 (decorado). Pasta antiplástica: Arena fina con cuarzo y biotita. Distribución: regular. Color de la pasta: anaranjado claro. Textura: compacta. Fractura: regular. Cocción: oxidante uniforme. Grosor promedio, $5.0 \mathrm{~mm}$. Medidas: alto total, $6.8 \mathrm{~cm}$, con asa; altura máxima del cuerpo, $4.5 \mathrm{~cm}$; ancho máximo, $15 \mathrm{~cm}$. Superficie externa: color anaranjado claro. Tratamiento: alisado. Interna: decoración con fondo café violáceo. Tratamiento: bruñido. Escudilla, sus paredes laterales externas indican un elipsoide en posición horizontal en la parte superior, el borde rompe la línea quedando éste en forma vertical. Forma de la base: esferoide y plana. Forma del fondo: cóncavo. Pintura ausente. Decoración pintada: Escudilla bicroma, con figura cruciforme interior de cuatro líneas convergentes del centro al borde de color blanco. Al centro se parecía una figura cruciforme de color negro de líneas sencillas. Los cuatro sectores en que se divide la pieza por la figura de líneas blancas, se encuentran decorados con finísimas líneas cruzadas entre sí, formando pequeños espacios en que se aprecia el fondo violáceo. Forma del borde: vertical y semicuadrada. Forma de la boca: esferoidal. Aditamentos: distribución y posición de las asas, se ubican en el borde, sobrepasando el nivel de éste en líneas verticales con un solo punto de unión. Pintura: fugitiva en algunos sectores. Decoración pintada. El asa entrega la siguiente decoración: líneas atravesadas y dos líneas de figuras cruciformes.

Tiesto 6 (decorado). Pasta antiplástica: arena con cuarzo y biotita. Distribución regular. Color de la pasta: anaranjado claro. Textura: compacta. Fractura: uniforme. Cocción: oxidante uniforme. Grosor promedio, $5 \mathrm{~mm}$. Medidas: alto total, $4.6 \mathrm{~cm}$; ancho máximo, $15 \mathrm{~cm}$. Superficie externa: decorada con fondo anaranjado. Tratamiento: alisado. Interna: 
color, decorada. Tratamiento: alisada. Forma general: escudilla elipsoidal en posición horizontal; el sector cercano al borde por su superficie exterior toma la línea vertical. Forma de la base: plana y esferoidal. Forma del fondo: cóncavo. Pintura: se observa pintura firme. Decoración pintada: escudilla bicroma con diseños decorativos interiores que afectan las siguientes figuras geométricas: a) líneas dobles que dividen la pieza horizontalmente en tres secciones; b) estas secciones diseñadas con pequeños rectángulos de puntos blancos puestos en forma vertical y separados uno de otro; c) la sección central inferior se encuentra decorada con un cuadro de líneas dobles; líneas en igual forma unen interiormente los cuatro ángulos de esta figura junto a puntos blancos interiores que demarcan los triángulos sobresaliendo notablemente. En las cuatro puntas exteriores se aprecian cuatro circunferencias pequeñas pintadas de negro, que completan la figura (toda esta descripción está basada en el 50\% de la pieza total). Forma del borde: semicuadrada con notoria inclinación hacia el interior de la pieza. Forma de la boca: esferoidal. Existe una protuberancia integrada al borde, con depresión en el centro y dos perforaciones, en el lugar opuesto se encuentra el asa.

Tiesto 7 (decorado). Pasta antiplástica: Arena con cuarzo y biotita. Distribución del antiplástico: uniforme. Color de la pasta: anaranjado. Textura: compacta. Fractura: regular. Cocción: oxidante uniforme. Grosor promedio, $5.5 \mathrm{~mm}$. Medidas: alto total, $4.2 \mathrm{~cm}$; ancho máximo, $9.7 \mathrm{~cm}$. Superficie externa: color, anaranjado con engobe. Tratamiento: bruñido. Interna: color anaranjado con engobe. Tratamiento: bruñido. Forma general: Escudilla ornitomorfa de forma elipsoidal en posición horizontal. Forma de la base: esferoidal y plana; forma del fondo: cóncavo. Pintura: en la superficie interna, firme; en la externa, fugitiva. Decoración: pintada; la forman pequeños auquénidos estilizados de color negro (monocromo) que afectan a toda la pieza. Forma del borde: semicuadrado. Forma de la boca: esferoidal. Presenta un mango ornitomorfo y bicromo con posición en el borde, sobrepasando el nivel del borde general de la pieza. Puesta en forma vertical y como posición en el borde, con un solo punto de unión.

Tiesto 9. Aríbalo. Pasta antiplástica: Arena con cuarzo y mica. Distribución del antiplástico: regular. Color de la pasta: anaranjado claro. Textura: compacta. Fractura: regular. Cocción: oxidante uniforme. Grosor promedio, 5 a $4 \mathrm{~mm}$. Medidas: alto total: $25.9 \mathrm{~cm}$, ancho máximo con asa $22 \mathrm{~cm}$. Superficie externa: color crema a café obscuro. Tratamiento: pulido con engobe. Interna: color anaranjado claro. Tratamiento: pulido. Forma general: zona del cuerpo, ovoidal, posición normal. Forma base: cónica de dos líneas convergentes. Zona del cuello: forma hiperbólica. Borde: redondo. Paredes: paralelas. Boca: esferoide. Aditamentos: asas, dos con posición en el cuerpo y en líneas vertical.

Tiesto 10 (decorado). Pasta antiplástica: Arena, feldespato. Distribución del antiplástico: regular. Color de tá pasta: café claro. Textura: compacta. Fractura: regular. Cocción: oxidante. Grosor promedio, $4.5 \mathrm{~mm}$. Superficie externa: color anaranjado. Tratamiento: alisado. Rasgo zona cuerpo: forma ovoidal en posición normal. Forma base: cónica, líneas terminan en un soporte hiperbólico. Decoración integrada a la superficie. En el sector superior del cuerpo lado contrario del asa se aprecia un diseño sobre el nivel de superficie en forma de "V", $4 \mathrm{~mm}$ alto y $3 \mathrm{~cm}$ cada raya. Zona cuello: borde evertido. Forma: ojival. Boca: esferoidal. Interior del cuello y borde: engobe color violáceo.

Tiesto 11 (decorado). Pasta: Antiplástica. Distribución antiplástico: uniforme. Color pasta: anaranjado. Textura: compacta. Cocción: oxidante uniforme. Medidas: altura, $10.5 \mathrm{~cm}$. Grosor promedio, $4 \mathrm{~mm}$. Superficie externa: color crema con decoraciones. Interna: anaranjada. Forma general: zona del cuerpo, ovoidal en posición normal. Forma de la base: esferoidal con una leve concavidad central. Forma del fondo: esferoidal levemente convexo. Pintura: decoración bicroma, negro y violáceo sobre crema que abarca desde el comienzo del cuello al sector inferior del cuerpo. En igual forma ocupan los espacios líneas diagonales en los extremos. Zona del cuello: forma del cuello, líneas divergentes. Forma del borde: medio ojival. Forma de la boca: esferoidal. Pintura: sector exterior, crema; sector interior, violáceo. Sector borde negro. Zona aditamentos: posición del asa, en el sector del cuerpo, sector superior, sobrepasa levemente el borde superior de la pieza, su forma interior afecta la figura ovoidal, dispuesta verticalmente. Pintura: deformación pintada, parte exterior de la asa, líneas verticales, horizontales y diagonales cortadas en forma de " $X$ ".

Tiesto 12. Similar al 11 (tiesto decorado). 


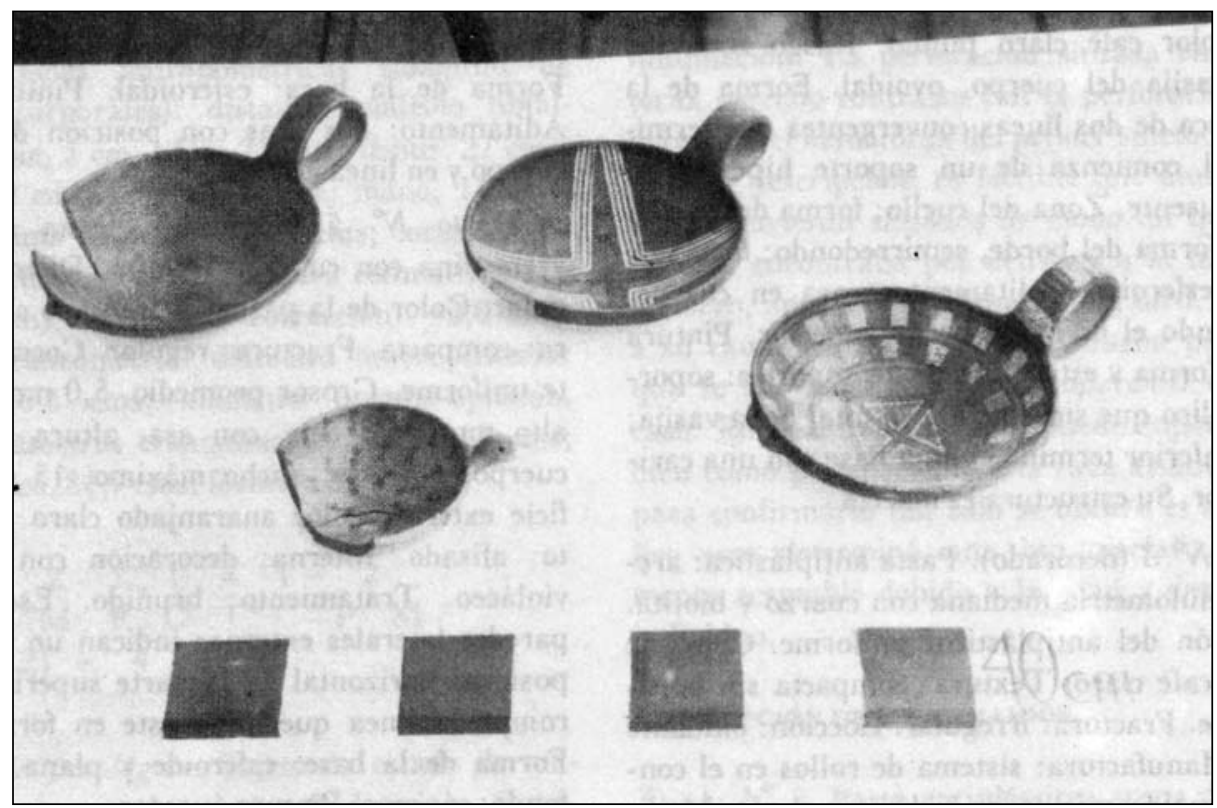

Figura 2. Platos.



Figura 3. Jarros.

Tiesto 13 (no decorado). Pasta antiplástica: Arena de granulometría mediana con cuarzo. Distribución del antiplástico: regular color de la pasta, café pardo, uniforme sin núcleo. Textura: compacta, sin bolsillo de aire. Fractura: regular. Cocción: oxidante uniforme. Medidas: alto máximo, $10.2 \mathrm{~cm}$. Grosor promedio, $5 \mathrm{~mm}$. Superficie externa: color anaranjado. Tratamiento: engobado y pulido. Interna; café pardo. Tratamiento: alisado con ramas vegetales. Forma general: zona del cuerpo (ánfora) ovoidal en posición normal. Forma de la base: líneas convergentes hacia el soporte hiperboloide. Pintura: ausente. Zona del cuello: forma del cuello: líneas divergentes. Forma del borde: redondo. Forma de la boca: esferoidal. Pintura: ausente. Zona aditamentos, posición asas: 1 asa, sector superior del cuerpo dispuesta en forma horizontal, se encuentra fracturada, sólo existen 
muñones. Sector opuesto al asa: una protuberancia con dos incisiones.

\section{Tiestos 14 y 15. Similar descripción al 13.}

Tiesto 16 (no decorado). Pasta antiplástica: Arena de granulometría mediana con cuarzo y biotita. Distribución: regular. Color pasta: café claro. Textura: compacta. Cocción: oxidante uniforme. Grosor promedio: $5 \mathrm{~mm}$. Medidas: altura máxima, $15 \mathrm{~cm}$. Superficie externa: engobe color crema. Interna: sector de la boca, color violáceo. Cuerpo: color anaranjado. Forma general: zona del cuello, ovoidal en posición normal. Forma de la base: esferoidal y plana. Forma del fondo: esferoidal y levemente convexo. Pintura: ausente. Zona del cuello: forma del cuello, hiperboloide, ocupando el $50 \%$ de su altura total. Forma del borde: semicuadrado. Forma de la boca: esferoidal. Pintura: sector exterior, crema; sector interior, violáceo; sector del borde, violáceo. Zona aditamento: asa en el cuello, en forma vertical. $\mathrm{Su}$ figura interior afecta la figura elipsoidal; color: crema, en general.

Tiesto 17 (decorado). Pasta antiplástica: Arena fina con cuarzo y biotita. Distribución: regular. Color de la pasta: anaranjado claro. Textura: compacta. Cocción: oxidante uniforme. Grosor promedio, $5 \mathrm{~mm}$. Medidas: diámetro, $14.7 \mathrm{~cm}$. Superficie externa: color anaranjado con sus bordes color violáceo. Interna: decoración sobre fondo violáceo. Tratamiento: alisado. Forma general zona del cuerpo: escudilla elipsoidal en posición horizontal. Forma del fondo: cóncavo. Forma del borde: semicuadrado. Pintura: escudilla con decoración bicroma. Interna: blanco y violáceo, líneas horizontales doble dividen la pieza en tres secciones, el fondo se destaca con un cuadrado en cuatro triángulos. Zona aditamentos: un asa con posición en el borde de la escudilla, con decoración violácea y blanca sobre fondo violáceo claro. El sector opuesto entrega una protuberancia con dos orificios, que no atraviesan el sector.

Tiesto 18 (decorado). Pasta antiplástica: Arena de granulometría con cuarzo y biotita. Distribución del antiplástico: uniforme. Color de la pasta: anaranjado. Textura: compacta. Cocción: oxidante uniforme. Grosor promedio, $5 \mathrm{~mm}$. Medidas: diámetro máximo, $8.8 \mathrm{~cm}$. Superficie externa color: café engobado; interna: decoración, color: violáceo sobre fondo de color anaranjado engobado. Forma general: escudilla. Forma de la base: esferoidal con leve convexidad. Forma del fondo: cóncavo. Forma del borde: redondo.
Pintura: diseño en la parte interna de la pieza, tres franjas de líneas dobles, atravesando el centro de color violáceo, sobre fondo anaranjado. Interior de las franjas: se aprecian pequeñas líneas rectas; el resto está adornada con pequeños elipsoides, pintados en forma rápida. Zona aditamentos: posición del asa, no posee; en su reemplazo cumple esta función un mango ornitomorfo (cóndor de alas extendidas) de color blanco en la parte dorsal y en el collar. En el resto del cuerpo es de color violáceo obscuro. Los dos ojos están presentados por dos pequeños orificios. Pieza fracturada.

Tiesto 19 (no decorado). Pasta antiplástica: Arena de granulometría mediana con cuarzo y biotita. Distribución del antiplástico: uniforme; color pasta: café. Textura: compacta. Cocción: oxidante parcial. Manufactura: burda. Medidas: diámetro máximo, $8.3 \mathrm{~cm}$. Grosor promedio, $6 \mathrm{~mm}$. Superficie externa: color anaranjado muy fugitivo con manchas de cocción. Tratamiento: engobado. Interna: color anaranjado muy fugitivo con manchas de cocción. Forma general: tipo escudilla muy burda, con figuras zoomorfas. Central destacada (para quemar incienso). Forma de la base: convexa. Forma del borde: redondo y muy irregular. Asas: una figura zoomórfica (cuello y cabeza de animal).

\section{Metales}

Los objetos metálicos rescatados están compuestos por una mayoría de piezas de plata. El oro está presentado por una lámina delgada utilizada como brazalete y anexada al ajuar del cuerpo adulto. Estas piezas no estaban en el antebrazo sino colgadas sobre los textiles, por la remoción intencionada que hicieron los operarios de la obra caminera. El brazalete de plata también se recogió muy fragmentado y disperso pero la oxidación argentífera del antebrazo izquierdo de la momia adulta no deja lugar a duda de su ubicación y uso.

Aparte de estos dos brazaletes, logramos reconstruir tres tupus de plata, también fragmentados, y algunos trozos de tubos para rapé del mismo metal.

Los dos cuerpos presentan marcas de oxidaciones argentíferas en los antebrazos que indican la exacta presencia de dos brazaletes más, que indudablemente se desintegraron durante la inexperta manipulación de extracción (encontramos algunos pequeños fragmentos). 
En los textiles hay marcas incisas y por oxidación que hacen suponer la existencia de cinco objetos más de plata, que tampoco están en nuestro poder. Esto eleva a siete las piezas extraviadas o desintegradas. Con excepción de una estatuilla de concha de Spondylus princeps y un trozo de pectoral del mismo material, no se encuentra presente la típica estatuilla de plata feminiforme o camelidiforme tan ampliamente difundida en este período Inca clásico y que aparecen en casi todos los sacrificios en las cumbres andinas. Esto no significa que debemos descartar su existencia y la posibilidad de que haya quedado en manos de particulares, ya que la información oral recogida entre los mismos trabajadores indica que ellos vieron dos muñequitos de piedra y metal.

Desgraciadamente, a los pocos días este personal terminó su faena y emigró a distintos puntos del país, siendo muy difícil su localización. De todas maneras, continuaremos esta pesquisa e informaremos oportunamente su aparición, si ésta se produce. En todo caso, hasta aquí hemos rescatado más del 95\% de los elementos del ajuar general.

Para concluir la información sobre los metales y antes de la descripción de los objetos mismos, debo decir que ninguno de los cuerpos presenta evidencias claras de perforaciones en los lóbulos de las orejas, por lo que descartaríamos en el principio la posibilidad de zarcillos metálicos o de otro tipo.

Brazalete de oro. Forma trapezoidal. Medidas: $8.8 \mathrm{~cm}$ más fallantes de $1.5 \mathrm{~cm}$, aproximadamente. Espesor: $0.5 \mathrm{~mm}$. Peso: $3 \mathrm{~g}$. Quilates: 22 quilates. Textura: lámina sin pulir. Color oro fundido, no existen aplicaciones extrañas al metal. Decoración: repujado cuadrangular muy irregular y alterado.

Brazalete de plata. Forma: trapezoidal. Medidas: $6.3 \times 9 \mathrm{~cm}$. Espesor: $0.5 \mathrm{~mm}$. Textura: lámina con pátina y oxidación. Color: natural; no existen aplicaciones extrañas al metal. Decoración: sin decoración.

Tupus de plata. Existen tres tupus de plata, algunos con faltantes del disco y un tercio de la agujilla. Uno de ellos tenía enlazado en espiral, una fina soguilla de lana de alpaca, y todo parece indicar que estos artefactos no estaban insertados en los textiles, sino más bien depositados encima de ellos, entre los pliegues del manto más importante (envoltura exterior).
Tal como ocurre con los descritos para los cerros El Plomo, Pili y Mercedario, los tupus de Esmeralda tienen una perforación en la base de la cabeza semicircular (disco) por donde pasaba el fino extremo de la soguilla de hilado circular que en todos los enterramientos de este tipo, descritos por diversos autores, aparecen como soporte para las dos pequeñas placas pectorales confeccionadas en concha de Spondylus princeps (Mostny 1957; Milan 1973: 43, 45).

En los tres primeros cerros mencionados se trata de miniaturas, en cambio en Esmeralda son artefactos utilitarios tal como ocurre con todo el ajuar de este enterratorio. Medidas: disco o cabeza, alto $5 \mathrm{~cm}$, ancho $6 \mathrm{~cm}$; agujilla, largo $25 \mathrm{~cm}$. Largo total del tupu: $30 \mathrm{~cm}$. Decoración: no tiene decoración de ningún tipo.

Tubo para rapé. Se observan fragmentos muy pequeños de láminas de plata cuya curvatura insinúa la forma de un tubo para rapé. Una de las tapas de estos tubos tiene $2 / 3$ de faltantes; no permite calcular su diámetro y altura. La segunda tapa de estos receptáculos está intacta, y en base a ella es que hemos realizado la reconstrucción de estos elementos.

Tal como hemos explicado, esta es una tumba excavada sin técnicas especiales por gente neófita y ajena a nuestra disciplina, por lo tanto el ajuar se presenta desordenado. Basándose en la marca dejada en los textiles por estos objetos, se puede deducir que se ubican entre el poncho grueso que sirvió de mortaja y el fino manto de la envoltura exterior, y estaban colocados en el tórax a la altura del esternón y cerca de las conchas de Spondylus princeps que habrían estado ubicadas a la altura de las mamas. Al igual que los tupus, los tubos y las conchas, están registradas para el cuerpo adulto.

La mano izquierda de esta momia presenta marcas de óxido de plata. Algunos fragmentos de este metal tienen adheridos trozos de materia orgánica (probable huella dactilar) que corresponde a la misma mano. Uno de estos pequeños trozos insinúa la forma circular de lo que se piensa que existió un tercer tubo de rapé, cuyas dimensiones no podemos hipotetizar.

\section{Conchas de Spondylus princeps princeps}

Las momias del Esmeralda contienen en su ajuar tres conchas de un molusco bivalvo que no pertenece a la fauna local y que en forma de estatuillas o adornos 
pectorales figura en casi todos los enterratorios de cumbres registradas a lo largo de la Cordillera de los Andes, desde nevado de Chachani, depto. Arequipa (Perú), hasta cerro El Plomo, cerca de Santiago (Chile).

El profesor Daniel Frassinetti, del Laboratorio de Paleontología del Museo Nacional de Historia Natural (Santiago), ha tenido la gentileza de determinar la especie. Entregamos un extracto de su informe:

a) Se trata de la especie Spondylus princeps princeps, de $9 \times 9 \mathrm{~cm}$, aproximadamente.

b) Su distribución geográfica es desde Panamá basta el norte del Perú, estando presente en toda la costa ecuatoriana.

c) Las conchas de Spondylus princeps princeps en su estado natural presentan unas numerosas y largas proyecciones espinosas encurvadas que salen ordenadamente desde toda su superficie externa, dándole al animal un notable aspecto erizado. La superficie interna lisa y pulida posee comúnmente delicados colores erizados en su capa nacarada, de gran belleza estética. Existen ejemplares bastante más grandes que las encontradas en el cerro Esmeralda.

ch)El género Spondylus es típicamente tropical y está representado por varias especies en las aguas tropicales sudamericanas, tanto en el lado del Pacífico como en el Caribe.

d) En las conchas encontradas en Iquique, las proyecciones de la superficie han sido totalmente pulidas y desgastadas. Su color corresponde al descrito para Spondylus princeps princeps: externamente de color anaranjado o rojo coral de manera uniforme. Una de las conchas presenta dos perforaciones muy cerca de vértices de unión, resultando muy probable su utilización como adorno pectoral; también con este material confeccionaron una pequeña placa trapezoidal que mide aproximadamente $5 \mathrm{~cm}$ (1/3 faltante), que para este caso está anexada al tupus de plata y no a la soguilla circular que inserta en los discos de este mismo artefacto.

Todo forma un solo conjunto, sólo que la ubicación de esta placa difiere con lo descrito por Mostny (1957: 52), quien es la única precisamente en el centro de la soguilla. Del centro del trenzado cuelgan dos trencitas sencillas, en cada una de las cuales está amarrada una pieza rectangular de concha de Spondylus. Su posición en la agujilla del tupu no altera en nada la clasificación general. Posteriormente rescatamos otra placa pectoral confeccionada también en Spondylus cuyas medidas son: largo, $5 \mathrm{~cm}$; ancho inferior, $2.2 \mathrm{~cm}$; ancho superior, $1.3 \mathrm{~cm}$. Tiene atado un cordón rojo quemado en un extremo. El quemar objetos como una forma de sacrificio está descrito por Beorchia (1973) para la mayoría de los enterramientos de cumbres en los Andes del Collasuyo.

En resumen, el ajuar de conchas se compone de tres conchas completas, una placa pectoral con faltante y una placa pectoral completa.

Según describe Garcilaso de la Vega (1606) el oro y la plata eran considerados como bienes patrimoniales por los incas. No constituían precisamente un tesoro en el sentido valorizado que nosotros entendemos. Solamente lo estimaban por su hermosura y resplandor, para ornato y servicio de las casas reales y templos del sol y casas de vírgenes.

Bartolomé Ruiz (1526) relata una embarcación incaica en el mar cargada con objetos de oro, plata y otras cosas de manufactura inca. Todo esto traían para rescatar por unas conchas de pescado de que ellos hacen cuentas coloradas como corales y blancas. Traían casi el navío cargado de ellas. Según esta evidencia, hay que considerar también esta segunda figurita (de Spondylus) como objeto de gran valor para su época (Mostny 1957).

La importancia de la concha de Spondylus princeps princeps está clara, ya que se encuentra presente en casi todos los sacrificios de cumbres descritas por otros autores y cronistas.

Materia orgánica. Algunas de las vasijas contenían materias orgánicas que fueron depositadas como ofrenda especial. También en este contexto se registran dos calabazas y se incluyen entre los receptáculos cinco chuspas o bolsas de lana cuyo contenido autoriza su ubicación en este capítulo. La descripción de estas últimas, como también de una pequeña miniatura en forma de capacho ${ }^{2}$ se hará en el área de textiles.

2 Especie de cesto muy difundido en la costa, confeccionado en fibra vegetal (totora) y armado con tres maderos curvos cruzados. Forma del borde: hexagonal. 
Muestra 1. Contenido de los ceramios: Totora molida y seca, $40 \%$; tierra con gran contenido de cuarzo y cloruro de sodio, $60 \%$.

Con estos materiales hicieron una pasta, amasando junto con la totora, con el mismo sistema que se usa para la fabricación de adobes. Estos pequeños paquetes de barro fueron depositados en la mayoría de los ceramios al conocer su forma interior. La pasta de totora y barro la clasificamos como material para la construcción de viviendas.

Muestra 2. Contenido de uno de los ceramios globulares: Semillas y hojas de molle y tamarugo (árboles regionales). Las vainas del tamarugo se utilizan como excelente forraje para el ganado, y la rama de éste, junto al molle, constituyen un excelente combustible. El molle y el espino se utilizan -en los tiempos modernos- para la fabricación de carbón vegetal. No poseo información de esta práctica en el periodo prehispánico de Iquique.

Muestra 3. Estas y las otras muestras siguientes corresponden a las chuspas. Ceniza de tubérculos "papa de chuño" (nombre local). Esta es la materia que denominan llipta y que utilizan para masticar las hojas de coca y extraer la droga.

Muestra 4. Cuatro chuspas (pequeñas bolsas) contenían hojas de coca y estaban llenas hasta el borde, con las hojas muy apretadas, resultando un paquete muy compacto.

Garcilaso relata, refiriéndose a las hojas de coca, que éstas eran un privilegio que el Inka otorgaba a los curacas y nobles más importantes, considerándose como un honor muy alto su posesión. Por esto mismo, el ofrendar las hojas en un rito funerario se justifican plenamente.

Muestra 5. Dos chuspas de lana de alpaca repletas de hojas de coca forradas exteriormente con Stipa sp., gramínea que denominan paja brava, de amplia difusión en el altiplano chileno. Se utiliza como forraje para el ganado menor y para la techumbre de las casas.

Muestra 6. Contenido de dos calabazas: Ceniza de conchas marinas levemente contaminadas con cloruros y carbonatos por exposición al microclima del enterratorio.
El quemar objetos que eran muy apreciados por ellos era una costumbre al parecer muy difundida, ya que el Centro de Investigaciones Arqueológicas de Alta Montaña de San Juan, Argentina (1973), entrega la información de estas evidencias en muchas cumbres del Collasuyo.

También Garcilaso, en sus comentarios reales menciona este hecho. Transcribo el párrafo, textual:

"Sacrificavan conejos caseros y todas las aves que eran de comer y sebo a solas, y todas las mieses y legumbres, hasta la yerva cuca, y ropa de vestir de la muy fina, todo lo cual quemaban en lugar de encienso...".

Además de dos de las conchas de Spondylus princeps princeps, una de las placas trapezoidales de pectoral también presentan signos de haber sido quemados parcialmente.

Tubo pirograbado. Un tubo de caña pirograbado con figuras geométricas sellado en un extremo por el nudo natural del vegetal. Sus medidas: alto, $18.5 \mathrm{~cm}$; diámetro, aproximadamente $3 \mathrm{~cm}$. Desafortunadamente este objeto fue recuperado recién en el mes de septiembre, y habiendo estado en poder de otras personas por más de seis meses se ha perdido todo vestigio de su probable contenido. En todo caso se trata de un tubo para colores, o para guardar alucinógenos.

Varios autores han descrito la costumbre de guardar algo muy sagrado, como los dientes de leche, las uñas y el primer corte de pelo. Posteriormente éstos se enterraban con el cadáver para que no tuviese problemas en buscarlos al resucitar. ¿No podría ser este tubo de caña el receptáculo donde guardaron estos elementos? Otros tubos similares aparecen registrados en el volcán Pichupichu en Perú y el cerro Chañi, en Jujuy, Argentina.

Objeto de madera. En el mes de septiembre también rescatamos una cucharita de madera de manufactura simple sin incisiones ni pinturas. Su única decoración es el tallado de la parte superior del mango que insinúa la típica greca escalonada que utilizaron los incas en casi todos sus diseños. Medidas: mango $15 \mathrm{~cm}$, caroleta oval $4.5 \times 3.5 \mathrm{~cm}$, largo total $18.5 \mathrm{~cm}$, alto máximo (caroleta) $2 \mathrm{~cm}$, alto mínimo (mango), $3 \mathrm{~mm}$. 
Calabaza. Están presentes en el ajuar dos calabazas que contienen cenizas de conchas. No se aprecia decoración de ninguna especie y una de ellas tiene en la tapa dos pequeñas perforaciones posiblemente destinadas a sostener una pequeña asa de lana.

Miniatura de capacho. Pequeño cesto (capacho) tejido en lana de alpaca, al contrario de los de tamaño normal que por lo general son confeccionados en base a fibras vegetales. Medidas: largo, $8.5 \mathrm{~cm}$; ancho, $4 \mathrm{~cm}$. Contenido: hojas de coca.

Esta miniatura estaba recubierta en su parte exterior por plumas de color café y es quizás la única pieza que resulta extraña en el ajuar, ya que representa un elemento de trabajo que no corresponde a la nobleza o clases privilegiadas del incario.

Fragmento de caña. Dos fragmentos de caña no identificados (¿maguey?), cuya utilidad práctica no es posible definir claramente a menos que se tratara de las orejeras que menciona Garcilaso (cap. XXIII: 45 del libro primero de sus comentarios reales). Fueron encontrados por el autor entre los pliegues de la ropa y se desconfía que ésta sea su posición original, ya que todo el ajuar fue revuelto por los operarios que realizaron el hallazgo.

Bermellón de cinabrio. Disperso entre los textiles y contaminando incluso algunos objetos de caña y chuspas el bermellón de cinabrio, elemento que posiblemente se usaba como maquillaje (las momias mismas no están pintadas). No encontramos ningún receptáculo, bolsa u otro elemento que pudiera haber contenido el bermellón, y pensamos que realmente no existió, puesto que no sería un objeto de interés para los operarios. Por la distinta oposición de los objetos contaminados cabe suponer que el cinabrio fue espolvoreado durante la ceremonia de sepultación.

\section{Textiles}

Tocado. Confeccionado en lana de alpaca y cubierto totalmente por pequeñas plumas blancas cosidas en hileras superiores, puestas de tal modo que no se aprecian los puntos de unión. Tiene forma cónica y las hiladas del tejido siguen la forma circular.

Colocado sobre la cabeza el cordón que forma el barbiquejo, cruza de una oreja a otra y ahí van insertadas las grandes plumas que conforman el penacho semicircular (como un abanico) que cruza todo el centro de la cabeza. El cordón que sostiene estas plumas, en el vértice del cono, forma una lazada que queda hacia el interior y que permitirá pasar por él un manojo de cabellos, los que luego remataban en la trenza. El tocado cubre absolutamente toda la cabeza hasta la nuca misma, pero tiene apéndice dorsal (ínfula), como ocurre con el descrito por Mostny (1957) para la figurita de El Plomo. La pieza presenta $1 / 3$ de faltante pero no ofrece problemas de interpretación, lo que nos permitió la reconstrucción ideal que presentamos.



Figura 4. Faja. 
Llautu. Anexada al cuerpo figuran tres llautus de lana de alpaca trenzados y terminados en cada extremo por una borla del mismo material. Los colores son amarillo y rojo. Medidas: diámetro, $1.5 \mathrm{~cm}$; largo, $1.27 \mathrm{~m}$ incluida la borla que mide $10 \mathrm{~cm}$.

Uno de ellos estaba colocado bajo la cabeza, otro bajo la cintura y otro en los pies.

Se trata, en realidad, de dos trenzas unidas entre sí por otra más delgada, lo que permite dar tres y media vueltas alrededor de la cabeza. Las medidas y los colores como así también la paicha (borla) se ajustan a lo descrito por Garcilaso, quien explica:

“...también fabricaban unas borlas pequeñas de dos colores, amarillo y colorado, llamadas paicha, asidas a una trenza delgada de una braza de largo, las cuales no eran para el Inka sino para los de su sangre real; traíanlas sobre cabeza, caían las borlas sobre la sien derecha."

Todos los colores del rico ajuar textil de esta momia son amarillo y rojo, con la sola excepción de unas pocas prendas sin teñir y que mantienen el color natural café y blanco de la lana. En cambio el cuerpo de la niña de nueve años está acompañado de un ajuar completamente pobre: es negro, con una variación en una faja amarilla con rojo y negro, con dos sogas terminadas en borlas en rojo y negro.

El cuerpo adulto tenía además un fragmento de cintillo compuesto de varias hebras de hilo muy fino acomodadas en forma desordenada y que no siguen un orden preestablecido. ¿Servirá para sostener más cómodamente el llautu, o el tocado?

Chuspas. En total ubicamos 10 chuspas o bolsas pequeñas para coca y dos talegas; pero en este capítulo describiremos las dos que venían cubiertas de plumas por la importancia que pudieran tener como aporte a una hipótesis de conclusiones de este trabajo. En general en todos los capítulos hemos actuado con el mismo criterio por considerar que algunos objetos materiales han sido estudiados amplia y exhaustivamente por otros autores:

a) Chuspa de lana de alpaca cubierta por plumas rojas de ave tropical dispuestas hacia abajo en siete corridas y cosidas con la puntada dando una vuelta alrededor del tallo. La lana de color café claro está tejida en una sola pieza que fue doblada y cosida con una costura muy fina de doble corrida en los costados. Medidas: largo $18 \mathrm{~cm}$, ancho $12 \mathrm{~cm}$; contenido: hojas de coca hasta la mitad de su capacidad. El borde superior está rematado por una costura también muy fina, pero esta vez la lana de alpaca es de color café obscuro.

b) Chuspa confeccionada con el mismo material de la anterior (lana alpaca) y con la misma técnica, sólo que ésta está cubierta con brillantes plumas verdes y es un poco más pequeña. Medidas: largo $15 \mathrm{~cm}$, ancho $10 \mathrm{~cm}$; contenido: hojas de coca completando su capacidad. Basándose en las marcas impresas en los tejidos y otros elementos del ajuar ambas bolsas debieron haber sido depositadas sobre los costados del tórax.

En resumen, los colores de las plumas que se registran en cerro Esmeralda son rojo, verde y blanco; las pequeñas plumas de miniatura del capacho son muy escasas.

Cobertor púbico. El cuerpo tenía en su ajuar cuatro argollas de lana de alpaca tejidas con esmero. Por tratarse de un elemento no descrito anteriormente, nos intrigó bastante su aplicación: encontramos dos de estas prendas circulares colocadas una en cada pierna y en la parte superior del muslo, precisamente en el pliegue de la pierna y la pelvis. Las dos argollas estaban unidas entre sí por un trozo delgado de cuero de animal que cubría exactamente el sector genital. Aquí supimos que se trataba de un muy especial cobertor púbico unido a dos especies de ligas femeninas tejidas de lana.

El cuerpo de la pequeña niñita no tenía colocada esta prenda, pero una de las ligas es de menor diámetro que las otras tres, ¿sería de ella o para ella?: Ya hemos dicho que el ajuar estaba confuso y revuelto. En todo caso, aun tratándose de una prenda de menor diámetro no se trata de una miniatura. Para conseguir la forma circular probablemente utilizaron el sistema que se usa para tejer macramé: la fina terminación del borde exterior presenta una serie de pequeños lazos, que aparte de constituir un adorno, sirve para unir al cobertor púbico de cuero. Las medidas de las ligas que tenía la momia son: ancho de la liga, $2.5 \mathrm{~cm}$; diámetro, $14 \mathrm{~cm}$; largo del cobertor de cuero: parcial $8 \mathrm{~cm}$ más faltante $4 \mathrm{~cm}$; total aproximado, $11 \mathrm{~cm}$; ancho máximo: $5 \mathrm{~cm}$.

Al examen microscópico aparecen adheridos al cobertor los vellos del sexo, lo que elimina la 
posibilidad de alguna almohadilla o paño, e indica su aplicación directa al genital. No hay rastros de sangre, por lo que se descarta el aspecto menstrual en el momento del sacrificio.

Aparte de las ligas que tenía colocada en el cuerpo, las otras son nuevas y ligeramente distintas entre sí. El hecho de no estar pareadas no debe preocuparnos, pues existe la posibilidad de que se hayan extraviado en el momento de la excavación. Lo mismo ocurre con el calzado (mocasines o chalas) que no se encuentra presente en el ajuar, incluso faltan partes de los pies, que se mutilaron durante la extracción.

Manto real. Esta denominación es arbitraria y cumple el único objetivo de descartarlo de los demás por su excelente manufactura y decoración. Otros autores les asignan a este tipo de prendas el de "camisón" y en algunos casos agregan "utilizados como poncho". No creo que éste sea el caso, puesto que la única costura que presenta es aquella que une ambas piezas del telar para formar un solo conjunto homogéneo sin abertura para la cabeza o mano.

Se trata de una pieza de mucho colorido y belleza, de textura delgada y que fue confeccionada para utilizarla como manto o rebozo sobre todo otro ropaje.

Descripción somera: En la policromía se destacan los colores rojo, amarillo y blanco. En la bibliografía que he revisado, estos colores eran permitidos exclusivamente a las clases superiores o reales o construían una privacidad otorgada en escasas oportunidades.

La decoración se presenta en franjas verticales, predominando los motivos geométricos. Los otros de secundaria importancia superficial son el café $y$ el verde.

En el amplio sector central $(40 \mathrm{~cm})$ de color blanco existe una clara evidencia de haber sido quemado intencionalmente produciendo faltante de más de $50 \%$ en este sector. Las marcas de quemaduras se repiten insistentemente en otros textiles y algunos otros objetos de ajuar, confirmando lo expuesto de que se trataría del sacrificio de los objetos al sol, además del sacrificio humano.

En este mismo sector se puede ver claramente, en los fragmentos deteriorados, la trama de color café oscuro de lana de alpaca y apreciando una fina y apretada urdimbre en lana de vicuña blanca que cubre totalmente la trama, que para este caso queda invisible.
Las franjas decorativas compuestas de 18 rectángulos presentan una relativa homogeneidad de diseños a base a figuras tipo zigzag con abundancia de pequeños cuadrángulos con puntos. Pero a lo largo de toda la franja solamente una vez se altera el sistema cuando aparece una figura en forma de "S" quebrada con solamente cuatro rectángulos pequeños. Esta variación bien pudo ser para acomodar un tamaño dado de la pieza, por exigencias del Tawantinsuyo. Las medidas de este elemento son: $1.65 \times 1.33$ (¿1.05?) y los cuatro de éstos que figuran en el ajuar (diferentes medidas) corresponden todos al inventario del cuerpo adulto.

Fajas. Siempre del contexto de la adulta joven entregaré la descripción elemental de dos fajas que presentan características especiales.

Faja a). Medidas: Largo $1.73 \mathrm{~m}$, ancho $14 \mathrm{~cm}$. Unida a un extremo lleva una soga trenzada que termina en una borla; todo es amarillo. El largo total de este cordón, incluida la borla, es de $1 \mathrm{~m}$. En la faja los colores predominantes son el rojo y el amarillo distribuido en cinco franjas longitudinales, de éstas los dos extremos y centros repiten un solo motivo geométrico de líneas quebradas con pequeños cuadrángulos alterados.

En dos franjas intermedias, los diseños geométricos son heterogéneos, abundando las formas de " $x$ " doble rombo y triangulares además de unos motivos antropomorfos. A diferencia de otras fajas ésta estaba colgada en el cuerpo ciñendo la cintura, inmediatamente sobre el camisón sudario y bajo el manto real. La mayoría de los otros elementos de este tipo estaban colocados como ajuar depositado.

Faja b). Medidas: Largo 1.23 m (ancho). Los colores son como casi todas las demás, el rojo y el amarillo, con algunos diseños en fondo negro; en este caso el remate del borde es de color verde. La decoración también está dispuesta en cinco franjas longitudinales. En este caso se sigue el sistema anterior de la continuidad de las franjas laterales y centrales repitiendo en ellas los mismos motivos geométricos de líneas quebradas sobre fondo amarillo (Figura 4).

Las franjas intermedias sobre fondo rojo presentan gran variedad de figuras, entre las que podemos distinguir: rombos especiales de "s" con pequeños cuadrángulos intercalados, una forma de "x", cuatro cuadriláteros, figuras zoomorfas (auquénidos), figuras antropomorfas esvástica en negro y en rojo, cinco triángulos (cuatro con vértice encontrado y 
uno central). Existen otras figuras geométricas de difícil interpretación.

Para el autor esta faja resulta curiosamente importante por la gran cantidad de motivos diseñados, que la hacen destacarse de todo el complejo textil.

Cordelillo trenzado policromo. Se trata de una prenda finamente tejida con el sistema elemental de cuatro pequeñas estatuillas colocadas sobre un tubo que entrega finamente un tejido circular. Está realizado con mucho esmero y remata en los extremos con una fina trenza de dos hebras confeccionadas en totora. Este extremo es el que inserta en los discos del tupu.

Su decoración es romboidal y sus colores predominantes: amarillo y rojo con pequeños espacios negros. Medidas: largo $40 \mathrm{~cm}$, diámetro $4 \mathrm{~mm}$, largo trenzado $24 \mathrm{~cm}$. Este cordón se utilizaba como un collar que pendía desde un tup $u$ a otro. Del centro deberían colgar dos pequeños cordones rematados en sendas placas trapezoidales de conchas de Spondylus princeps princeps.

En la momia del Esmeralda la única placa pectoral que rescatamos estaba colocada entre los pliegues del manto real y con indicios de haber sido quemada parcialmente. Una descripción muy completa de un cordón similar la realiza Mostny (1957: 52).

Estola dorsal. Especie de estola de lana de alpaca color café natural, cubierta totalmente con plumas verdes, dispuestas en 12 corridas separadas por $7 \mathrm{~cm}$ una de la otra. Las plumas cubren las costuras que se mantienen invisibles. Está rematada en la parte inferior por flecos de lana retorcida. Medidas: largo $86 \mathrm{~cm}$, largo fleco $24 \mathrm{~cm}$, largo total $1.10 \mathrm{~m}$, ancho $34 \mathrm{~cm}$. Esta pieza se usaba cosida al manto real en la parte superior de tal manera que pendía desde la base del cuello de la persona hasta un poco más abajo de la mitad del muslo.

Borla lana de alpaca. Está compuesta por un paquete de moño central, el que a su vez está recubierto por una capa exterior de hebras rematada por un apretado de hilo color azul índigo. Algunas de las trencillas de la borla presentan evidencias de quemadura.

El moño central o núcleo está compuesto de 12 soguillas y la capa exterior de 41, éstas no se encuentran trenzadas sino torcidas. Este tipo de borlas son las que se utilizaban para rematar el peinado de la momia (cada momia tiene colocadas dos). El peinado organizado en dos sectores con una partidura central remata atrás en dos guías de pelo torcido (uno trenzado). Desde el comienzo de esta guía y anudado el pelo se encuentra un hilo delgado pero muy resistente que sirve en la parte inferior para sostener la borla. Este hilo viene por dentro y es invisible desde el exterior, la longitud del peinado es de $16 \mathrm{~cm}$ y de la borla $5 \mathrm{~cm}$.

\section{Conclusiones}

El motivo de este artículo fue dar un minucioso registro de los diversos elementos que componen el ajuar y de las condiciones en que éstos se encontraban. De acuerdo a los elementos del ajuar, debemos ubicarlo en un período que iría desde 1450 a 1500 DC.

Dauelsberg (1969) ubica la cerámica Saxamar del Horizonte Inca, en el año 1450. El complejo cerámico del Esmeralda posee un pequeño plato ornitomorfo en decoración y técnica tipo Saxamar.

Las momias presentaron evidencias de haber sido estranguladas al igual que la del cerro El Toro, de la provincia de San Juan (Argentina). El hecho de que existen dos cuerpos en una sola tumba, nos entrega, junto a la realidad de un doble sacrificio, la alternativa de que el cuerpo de la adulta joven haya pertenecido realmente a una clase social privilegiada y que al ser seleccionada para esta inmolación, se haya escogido también a su pequeña servidora para que la acompañara. La diferencia de calidades de ambos ajuares confirmaría esta hipótesis. Para mayor consolidación de esta idea, el tocado cónico de plumas, que tenía el cuerpo adulto y que coincide con el que visten las figurillas femeninas de plata del cerro El Plomo y Pili, es similar a las descripciones tan difundidas para las miniaturas de este tipo.

El estrangulamiento coincidente con el cerro El Toro sólo debe considerarse como causa de muerte, puesto que en ese caso se trata de un cuerpo de sexo masculino y de otra condición social.

En el inventario figuran 104 piezas, pero estimo conveniente insistir en que el material en algunos casos se presenta confuso por lo irregular de su recuperación. Por este motivo no podemos separar aquello que es vestimenta de uso absoluto, de lo que verdaderamente constituye el ajuar depositado en forma adicional. Pero la diferencia textil entre la niña y la adulta está clara por las prendas que hallamos 
sobre sus cuerpos. Esta confusión obliga a registrar las ofrendas cerámicas como algo común a todo el enterramiento, aunque de todas maneras existen marcas muy definidas en los textiles del cuerpo adulto que, evidentemente, señala con toda claridad la depositación de ceramios en él. Lo mismo sucede con las conchas de Spondylus princeps princeps que claramente fueron depositadas sobre las mamas de esta momia. En cambio en el cuerpo de la niña de nueve años estas marcas no aparecen.

El calzado no se menciona, ya que desgraciadamente durante la excavación realizada por los operarios de la firma constructora se mutilaron los pies de ambos cuerpos, y cabe suponer su destrucción o extravío.

Los textiles del cuerpo adulto son muy finos y tejidos con esmero. Los colores predominantes son el amarillo y el rojo, los que según Garcilaso fueron los que se otorgaron a la nobleza del incario, indicando además que este tipo de prendas eran tejidas en Cusco por mujeres escogidas.

Mostny (1957: 57) afirma que tanto la túnica como la manta que lleva puesta el niño del Plomo son hechas de un género bastante tosco. Esto indica que el género no ha sido fabricado en Cusco o por algunas de las mujeres escogidas. Mostny ubica esta momia en algún lugar del Collasuyo. En el Esmeralda la ropa de la niña es un poco más burda que la del adulto, pero tiene también una faja con colores amarillo y rojo, con la diferencia que los dos cordones trenzados que allí vienen incorporados, están teñidos en rojo y negro, colores que utilizaron aquellas personas seleccionadas pero de menor alcurnia.

Por todo esto, es posible suponer que ambas proceden de Cusco, más aún si consideramos que anexado al ajuar del cuerpo de la niña aparece un fragmento de tocado circular cónico, sin revestimiento de plumas y mucho más tosco que el del adulto, pero tejido con la misma técnica y conservando la forma.

Todos los cronistas de la época coinciden en que el tocado era diferente para cada región, el que actuaba como distintivo obligatorio para diferenciar a unos de otros. En este caso los tocados son iguales y difieren de los que están descritos para el Collasuyo y coinciden con los de Cusco. El tocado de plumas es exactamente igual al que tiene puesta la miniatura femenina de plata de los cerros El Plomo y Pili, siendo, sí, la única diferencia el color de las plumas, que para este caso son blancas.
Las 104 piezas del ajuar, la elegancia y fina terminación tanto de las cerámicas como de los textiles, los depurados diseños, el símbolo esvástico de las fajas, los brazaletes de oro y plata, así como las tres conchas de Spondylus princeps princeps, confirmarían para la momia del Esmeralda su riqueza o privilegiada posición social.

Nos hemos preguntado repetidamente ¿por qué se escogió un cerro de la cordillera de la Costa para este sacrificio? A esta interrogante sólo podemos poner algunas conjeturas que por su misma lógica nos parecen aceptables:

a) El cerro Esmeralda, frente a la ciudad de Iquique, es el más alto del cordón y no tiene obstáculos geográficos de altura hacia el este, lo que permite que él sea el primero en iluminarse con el sol naciente.

b) La metalurgia fue siempre para el Inka un motivo importante de explotación, aun cuando el oro y la plata no fueron para ellos un motivo especial de riqueza personal; estos metales tenían significación extraordinaria para presentarlo como ofrendas a las divinidades o al hijo del sol. En todo caso, eran utilizados como adornos o utensilios por las castas privilegiadas o para transacciones muy especiales.

La mina de Huantajaya, en el área de Iquique, de larga y documentada tradición, era también de un rendimiento importante y fue explotada con cierta intensidad por el incario para extraer plata.

Esta mina está ubicada en el cordón cordillerano al que pertenece el cerro Esmeralda, inmediatamente al norte del cerro Huantajaya donde se encuentra la falla tectónica denominada Quebrada de Huantaca y que serpenteando en una suave pendiente pasa al lado sur del cerro Esmeralda y constituye un cómodo acceso tropero a Iquique. Se puede conjeturar entonces que en la selección de esta cumbre influyó la importancia de la mina Huantajaya.

c) Mario Cruz Bustamante, investigador de folclore, nos ha dado una información oral que aporta nuevos antecedentes a estas conjeturas. Relata el señor Cruz que en el pueblo de Cariquima, ubicado en el altiplano chileno de la I región, existe un grupo ceremonial llamado Los Sicuras, que en algunas oportunidades del año (no especificó cuáles) se reúnen sobre una pequeña loma, donde existen pircas y un altar central de piedra. Al salir el sol uno de ellos inicia las loas a los cerros sagrados del sector, dándoles las gracias 
por los beneficios que de ellos reciben o porque son depositarios de la morada de los dioses.

En esta oportunidad nombran también al cerro Huantajaya por sus riquezas. Estos hechos han sido comprobados por el autor.

Consultando a los lugareños sobre por qué veneran un cerro que está tan lejos de su sector, contestan simplemente "por su riqueza" y agregan la leyenda de que antes el cerro Huantajaya estaba junto a los otros, pero cuando pelearon el Isluga, Tata Sabaya, Tata Jachura y otros, expulsaron al Huantajaya que vino a dar a la costa.

El cerro Esmeralda y el Huantajaya están muy cerca y en un mismo cordón cordillerano, siendo fácilmente confundibles como un solo cerro con varias cumbres, descartando como la más alta la del cerro Esmeralda.

Si el mineral argentífero servía para confeccionar las estatuillas y otros elementos de sacrificios al Sol, se comprende que hayan escogido al complejo de cerros del Huantajaya para este sacrificio máximo.

d) El señor Cruz, además, nos ha dicho que en el año 1965 subió deportivamente a la cumbre del cerro Esmeralda y pudo ver una pequeña apacheta y algunas pircas. En aquella oportunidad no prestó demasiada atención a ello y es por eso que no pudo describirla más minuciosamente. Es conveniente registrar el hecho, puesto que las evidencias arqueológicas de superficie fueron borradas por los operarios de la construcción.

e) Según la gramática y vocabulario de la lengua aymara (de Torre 1616), la palabra iquitha o ikña significa dormir pero ikña también significa cama.

La palabra Iquique tiene la raíz "ique" que se utiliza para todas aquellas que significan dormir, acostarse: ¿tendrá esto alguna coincidencia toponímica con las momias del cerro Esmeralda? No podemos olvidar que ellos no pensaban en la muerte como el fin de una etapa, sino más bien como un sueño del cual habrían de despertar y para lo cual se preparaban durante toda su vida, guardando incluso los cortes de pelo y uñas.

Finalmente quiero destacar que de los 41 enterramientos de cumbre (incluido el del cerro Esmeralda) solamente dos se registran en Perú y el resto en el sector que fue el Collasuyo. A propósito de esto, Antonio Beorchia, del Centro de Investigaciones Arqueológicas de Alta Montaña de San Juan (Argentina), insinúa que más que una costumbre inca podría tratarse de una tradición colla adaptada posteriormente por los quechuas, basándose en la premisa de que los incas cuando conquistaban un territorio, respetaban las costumbres locales.

Personalmente opino que bien pudo tratarse de una costumbre eminentemente inca y que se escogió el Collasuyo y una parte del Contisuyo, como principal sector ceremonial, por encontrarse dentro de sus límites las más altas cumbres del Tawantinsuyo.

Agradecimientos El autor expresa su especial agradecimiento a los investigadores que han colaborado con sus conocimientos especializados, paciencia y dedicación a la realización de este trabajo. En especial cabe mencionar a Raúl Torres, quien realizó el informe anatomopatológico; Italo Lanino, por el estudio de fibras textiles; Octavio Morales y Olaf Olmos, por sus ayudas en el análisis y descripción de la cerámica, como también en la historia de la conservación y restauración de la misma. Como consultores han sido de especial valor las siguientes personas: Dra. Grete Mostny, R.P. Gustavo Le Paige, Lautaro Núñez, Dr. Carlos Antonio Viviani y el profesor Daniel Frassinetti. 


\section{REFERENCIAS CITADAS}

BAUDIN, L., 1972 [1940]. El imperio socialista de los incas. Roda, Madrid.

BEORCHIA A., 1973. La arqueología de alta montaña. Centro Investigaciones Arqueológicas de Alta Montaña, San Juan.

BORGEL, R., 1965. Mapa geomorfológico de Chile. Universidad de Chile, Santiago.

CASTILlO, N. y LITVAK, J., 1968. Un sistema de estudios para formas de vasijas. México D. F.

CERAM, C., 1965. Dioses, tumbas y sabios. Barcelona.

DAUELSBERG, P., 1969. Secuencia cultural y cuadro cronológico de la zona de Arica. Actas del V Congreso Nacional de Arqueología, La Serena.

DE LA VEGA, GARCILASO, 1960 [1604]. Comentarios reales de los incas. Biblioteca de Autores Españoles, vol. 133, Madrid.

DE TORRE, D., 1967. Arte de lengua aymara. Actualización de Mario Franco Inojosa, Lima.

FUENTES, J., 1965. Tejidos prehispánicos de Chile. Editorial Andrés Bello, Santiago.
HAD, P., 1952. Técnica de la cerámica. Barcelona.

LA PORTE, J. P., 1972. Diagramas de Venn. México D. F.

LOPEZ, E., 1965. La deformación intencional cefálica en los antiguos habitantes del departamento de Oruro. Universidad Técnica, Oruro.

MOSTNY, G., 1957. La momia del cerro El Plomo. Boletín del Museo Nacional de Historia Natural XXVII (1).

NOVOA, A., 1970. Cuadrángulos Iquique y Caleta Molle. Instituto Investigaciones Geológicas, Santiago.

PLENDERLEITH, H., 1967. Conservación de antigüedades y obras de arte. España.

SILVA, O., 1971. Prehistoria de América. Editorial Universitaria, Santiago.

VARIOS AUTORES, 1963. Congreso Internacional de Arqueología de San Pedro de Atacama. Anales de la Universidad del Norte 2.

1969. La conservación de los bienes culturales. UNESCO, Geneva.

WORMALD, A., 1968. Frontera norte. Editorial Orbe, Santiago. 